\title{
Robotic transperitoneal adrenalectomy from inception to ingenuity: the perspective on two high volume endocrine surgery centers
}

\author{
Murat Ozdemir ${ }^{1}$, Ahmet Cem Dural ${ }^{2}$, Nuri Alper Sahbaz ${ }^{2}$, Cevher Akarsu ${ }^{2}$, Can Uc $^{1}$, Berk Sertoz ${ }^{1}$, \\ Halil Alis ${ }^{3}$, Ozer Makay ${ }^{1}$
}

${ }^{1}$ Division of Endocrine Surgery, Department of Surgery, Ege University, Faculty of Medicine, Izmir, Turkey; ${ }^{2}$ Department of Surgery, Bakirkoy Dr. Sadi Konuk Training and Research Hospital, University of Health Sciences, Faculty of Medicine, Istanbul, Turkey; ${ }^{3}$ Department of Surgery, VM Medical Park Hospital Florya, Istanbul Aydin University, Faculty of Medicine, Istanbul, Turkey

Contributions: (I) Conception and design: All authors; (II) Administrative support: All authors; (III) Provision of study materials or patients: All authors; (IV) Collection and assembly of data: All authors; (V) Data analysis and interpretation: All authors; (VI) Manuscript writing: All authors; (VII) Final approval of manuscript: All authors.

Correspondence to: Dr. Ozer Makay. Ege University Hospital, Ankara Street, Bornova, Izmir, Turkey. Email: ozer.makay@ege.edu.tr.

\begin{abstract}
Background: With increased utilization of robotic technology, robotic adrenalectomy (RA) became popular in certain high-volume centers as an alternative to conventional laparoscopic adrenalectomy (LA). The aim of the present study was to evaluate clinical and surgical outcomes of RA in two high-volume centers in Turkey.

Methods: Between 2012 and 2019, consecutive patients who underwent robotic transperitoneal adrenalectomy in two referral centers for surgical endocrine diseases in Turkey were analyzed retrospectively. Results: A total of 111 patients were analyzed. Mean diameter of the tumor in preoperative imaging was $38.6 \pm 2.0 \mathrm{~mm}$. Total operation time was $135.4 \pm 47.9 \mathrm{~min}$. The analysis of the learning curve period and the post-learning curve period in both centers demonstrated that the total surgery time decreased from $152.68 \pm 48.6$ to $118.8 \pm 37.1 \mathrm{~min}$, and the console time decreased from $113.2 \pm 38.9$ to $81.6 \pm 35.1 \mathrm{~min}$ $(\mathrm{P}<0.0001)$. In 8 patients, complications arose during the surgery and postoperative complications were observed in 10 patients. Intraoperative complication rate was $28 \%$ in patients with a tumor diameter of greater than $50 \mathrm{~mm}(\mathrm{P}<0.0001)$. There was no mortality.
\end{abstract}

Conclusions: Our study demonstrated that RA is a safe and effective procedure with low-morbidity and without mortality in high number of cases.

Keywords: Endocrine surgery; adrenalectomy; robotic transperitoneal adrenalectomy

Submitted Dec 11, 2019. Accepted for publication Feb 13, 2020.

doi: $10.21037 /$ gs.2020.02.21

View this article at: http://dx.doi.org/10.21037/gs.2020.02.21

\section{Introduction}

Since the introduction of transabdominal laparoscopic adrenalectomy (LA) by Gagner et al. (1) in 1992 and retroperitoneoscopic adrenalectomy by Mercan et al. (2) in 1995, these two techniques became the standard in adrenalectomy care. Laparoscopic approach has proven to provide earlier ambulation, shorter hospital stay, faster return to normal activities, and less blood loss when compared to an open surgery (3).

Adrenalectomy is a complex operation technique that entails meticulous dissection around major vascular structures and organs (4). There are some important factors to conduct minimally invasive surgery on the adrenals successfully: optimal exposure of the adrenal area that is achieved by the endoscopic approach, the magnification that is mostly beneficial throughout the dissection of an 
anatomically complex area such as retroperitoneum, adrenal vascular supply that is well defined laparoscopically, and adrenalectomy that is an ablative procedure and suitable for an endoscopic approach (5).

Although generally accepted, laparoscopy has certain drawbacks such as two-dimensional view, unstable camera platform and rigid instrumentation (6). With the increased use of robotics, robotic adrenalectomy (RA) became common in certain high-volume centers as an alternative to conventional LA. The advantages of the robotic system in adrenalectomy include bimanual wristed instrumentation, a three-dimensional high-definition view, tremor-filtration, and individual camera operation. Furthermore, studies that analyzed the learning curve for laparoscopic and robotic adrenalectomy demonstrated a plateau after 30 LA cases, 20 RA cases (Brunaud et al.), and only 12 RA cases (D'Annibale et al.) (7-9).

The advantages of robotic technology over conventional laparoscopy and the expected faster learning curve in robotics allow the surgeons to carry out a complex but minimally invasive dissection in a deep and narrow area (10). These advantages could theoretically improve the LA procedure and result in improved peri- and postoperative outcomes. Certain studies suggested that patients with prior abdominal surgery, tumor size $>5 \mathrm{~cm}$ and $\mathrm{BMI}$ $>30 \mathrm{~kg} / \mathrm{m}^{2}$ were good candidates for robotic surgery (8-11).

Despite certain advantages of robotic technology over the conventional laparoscopy, it has not been widely accepted globally due to additional costs and controversies about the most appropriate indications (12). And large series that evaluated RA are currently not available.

The aim of the present study was to evaluate clinical and surgical outcomes of RA in two high-volume centers in Turkey.

\section{Methods}

\section{Study population}

All consecutive patients who underwent RA between 2012 and 2019 for surgical endocrine diseases in two referral centers in Turkey (Ege University, Faculty of Medicine, Department of Surgery, Izmir; University of Health Sciences, Faculty of Medicine, Bakirkoy, Dr. Sadi Konuk Training and Research Hospital, Department of Surgery, Bakirkoy, Istanbul) were screened for inclusion in the current chart review. All patients who underwent RA between the age of 18 to 80 with an adrenal mass that required surgery based on size, hormonal activity, and radiologic features including isolated adrenal metastasis of another malignancy were included in the study. Exclusion criteria were unsuitable cases for minimally invasive surgery, suspicion of primary adrenal carcinoma, and presence of a metastatic disease that requires extended resection.

Patient demographics, surgical and medical history, comorbidities, body mass index (BMI), American Society of Anesthesiologists (ASA) score, preoperative diagnosis, diameter and localization of the tumor, operative time, estimated blood loss, conversion rate to laparoscopic or open surgery, morbidity and mortality rates, length of hospital stay, re-admission to the hospital and postoperative histopathologic findings were retrospectively evaluated.

In both institutions, perioperative management of the patients was similar. Functional hormonal profile tests and imaging studies were conducted by the Department of Endocrinology or Surgery. All cases were discussed in the multidisciplinary adrenal tumor board that includes general surgery, endocrinology, pathology, radiology and nuclear medicine specialists prior to the surgery. Patients with preoperative Cushing's manifestations were operated under the appropriate steroid treatment protocol. Patients with pheochromocytoma were prepared for the surgery with alpha- and beta-blockers under similar protocols in both institutions. Postoperatively, all patients received a standard dose of analgesia and their Visual Analog Scale (VAS) scores were recorded. When they received preoperative steroids, the maintenance dose was continued. Follow-up visits were conducted in endocrinology and general surgery outpatient departments during the first week after discharge.

\section{Operative technique}

In both institutions, experienced robotic and endocrine surgeons performed all the procedures. All console surgeons had completed their training in accordance with Intuitive certification pathway. All procedures were conducted with daVinci ${ }^{\circledR}$ Robotic Surgical System (Intuitive Surgical Inc., Sunnyvale, CA, USA). The first 11 cases at Bakirkoy Training and Research Hospital, and all cases at Ege University were performed with the Si system, and the remaining cases at Bakirkoy were performed with the $\mathrm{Xi}$ system. Before using the $\mathrm{Xi}$ system, all console surgeons at the institution were trained for the $\mathrm{Xi}$ system that pertained online and live training with the new docking setup mock-up.

All procedures were performed under general anesthesia 

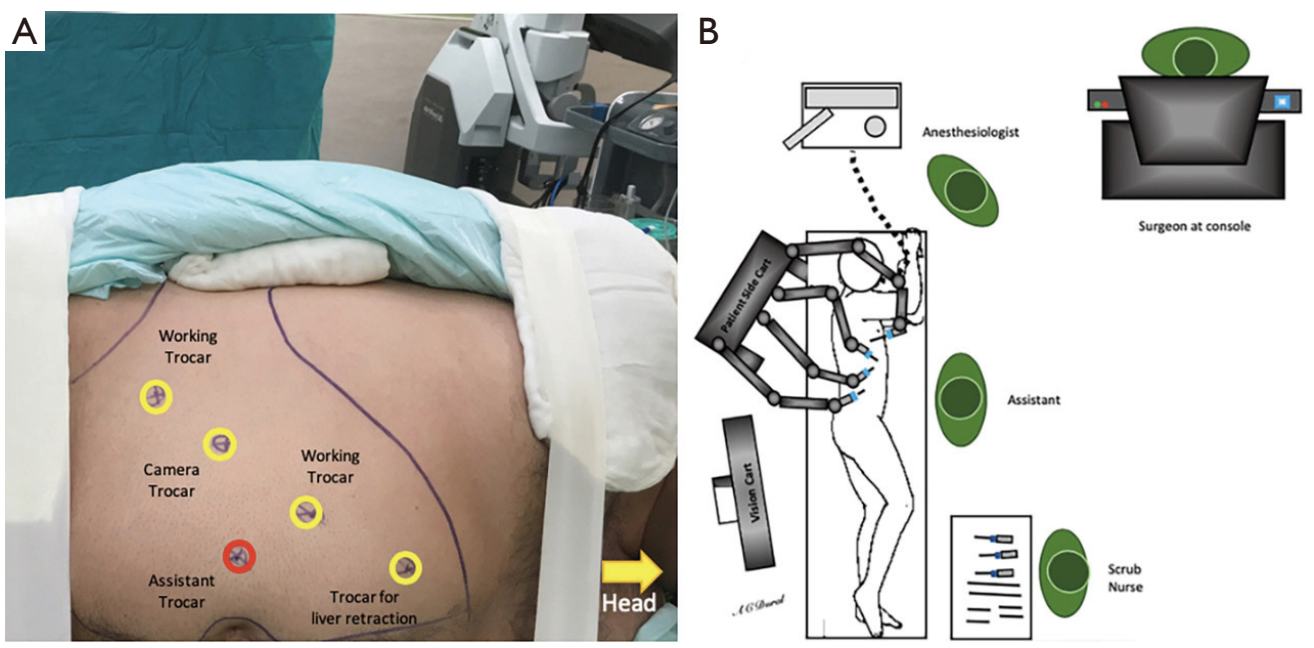

Figure 1 Placement of the trocars (A) and position of the robotic surgical team in the operating room for robotic transperitoneal right adrenalectomy (B).
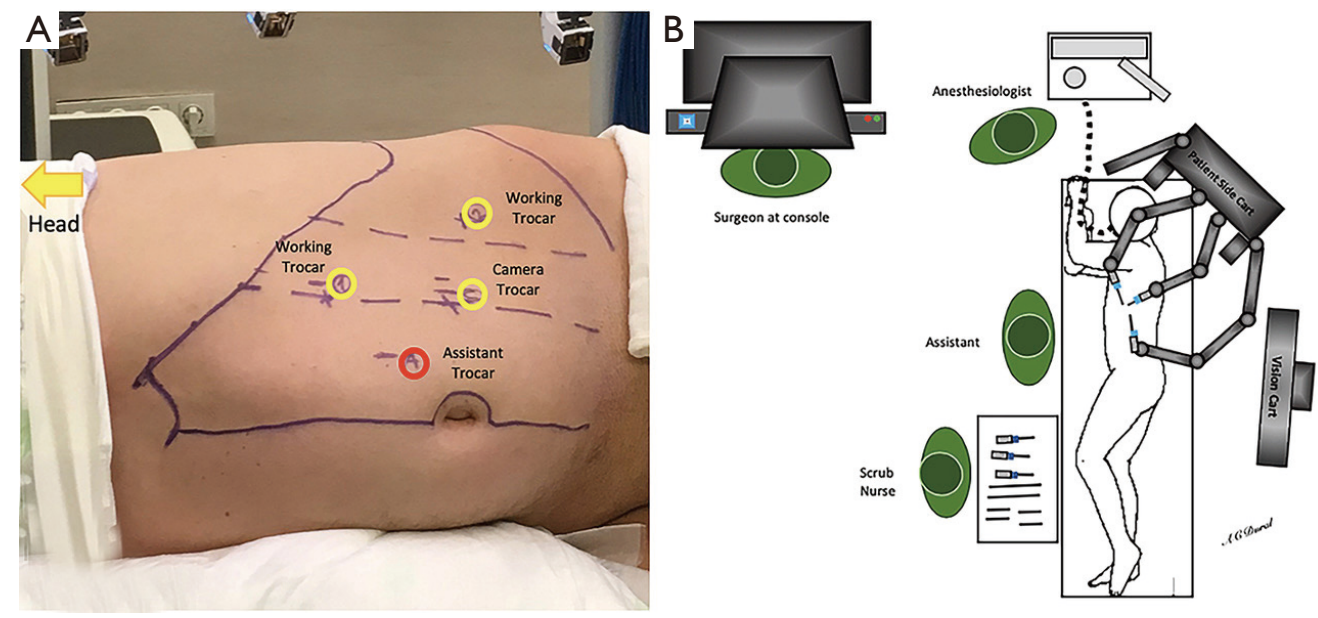

Figure 2 Placement of the trocars (A) and position of the robotic surgical team in the operating room for robotic transperitoneal left adrenalectomy (B).

with the transperitoneal approach. Patients were placed in a lateral decubitus position, the table was flexed at kindey level, and a supportive gel roll was positioned under each case. Operation room setting and trocar placement were lined with the side of the adrenal mass (Figures 1,2). The pneumoperitoneum was created with an open technique, and a $12-\mathrm{mm}$ trocar was inserted for the robotic camera. Two 8-mm trocars were used for the robotic arms (working instruments) and a paraxiphoid 5-mm trocar (13) or 8-mm robotic arm (14) were placed in a curved subcostal line for the retraction of liver in right adrenal cases. The robot was placed over the ipsilateral shoulder of the patients. The robotic arms were angulated to the port sites, and the trocars were docked. An additional trocar was placed near the umbilicus for assistance purposes (clip applier, energy device, suction etc., when required). Fenestrated bipolar forceps and permanent electrocautery hook with EndoWrist (Intuitive Surgical Inc., Sunnyvale, CA, USA) were used for the dissection of the adrenal gland. After the robot was undocked, the specimen was removed with an EndoCatch (Medtronic, Mansfield, MA, USA) specimen bag through the paraumbilical trocar. The robotic procedure details 
that were implemented with the daVinci Si system were previously described by both institutions $(11,12)$. Excluding the docking and linear trocar placement, the operative technique was similar in the $\mathrm{Xi}$ system. Also, the $\mathrm{Xi}$ robot was side docked ipsilaterally instead of diagonal placement to the ipsilateral shoulder with the Si robot.

\section{Ethics}

All procedures conducted in this study that involved human subjects were in accordance with the ethical standards depicted by the Bakirkoy Dr. Sadi Konuk Training and Research Hospital Ethics Committee (Registration Nr: 2019-01-19), with the 1964 Helsinki Declaration and later amendments, and compatible ethical standards. Informed consent was obtained from all participants in the study.

\section{Statistical analysis}

All study data were separately entered in a database (Excel ${ }^{\circledR}$, Microsoft Office) at both clinics and finally all data were merged anonymously. Statistical analyses were conducted on a software (SPSS version 25, IBM Corporation, Armonk, NY, USA). Continuous variables were expressed as mean $\pm \mathrm{SD}$ or median and interquartile ranges. Categorical variables were expressed as frequencies and percentages. Student's $t$-test was used to compare parametric continuous variables, and the Mann-Whitney $U$ test was used to compare nonparametric variables. Categorical variables were compared with the Chi-Square test. $\mathrm{P}$ values of 0.05 or less were considered statistically significant.

\section{Results}

The records of 111 patients (77 females, 34 males) who underwent RA between 2012 and 2019 were evaluated in the present study. Median patient age in both centers was 47 [21-74] years. Mean BMI value was $27.5 \pm 5.9 \mathrm{~kg} / \mathrm{m}^{2}$. The preoperative ASA scores of the patients were as follows: 22 patients $(19.8 \%)$ were evaluated as grade I, 67 patients $(60.4 \%)$ as grade II, 21 patients $(18.9 \%)$ as grade III and 1 patient $(0.9 \%)$ as grade IV. There was a statistically significant difference between the two centers based on ASA scores $(\mathrm{P}=0.0004)$. Furthermore, the evaluation of patient comorbidity with the Charlson Comorbidity Index (CCI) demonstrated that the mean score was $3.4 \pm 1.4$. Thirtysix patients $(32.4 \%)$ had a history of previous abdominal surgery. Mean diameter of the tumor was determined as
$38.6 \pm 2.0 \mathrm{~mm}$ with preoperative imaging. Fifty-six patients $(50.4 \%)$ had tumor on the right side, 53 patients $(47.8 \%)$ had tumor on the left side, and 2 patients (1.8\%) had bilateral tumors. Based on preoperative hormonal activity, operations were performed on 36 patients $(32.4 \%)$ for pheochromocytoma, on 27 patients (24.3\%) for Cushing syndrome, and on 17 patients (15.3\%) for Conn's syndrome. Out of 31 (28\%) patients with hormone inactive tumors, 5 had solitary adrenal metastases. The rate of pheochromocytoma was higher in Ege cases $(\mathrm{P}=0.007)$ (Table 1).

Mean operative times at both centers were as follows: Surgical set-up time was $30.35 \pm 16.5 \mathrm{~min}$, docking time was $9.4 \pm 5.5 \mathrm{~min}$, console time was $92.1 \pm 38.3 \mathrm{~min}$, and total operative time was $135.4 \pm 47.9 \mathrm{~min}$. Comparison of the two centers demonstrated that the first center (Ege) had completed the robotic surgery learning curve and was considered experienced, and the second center (Bakirkoy) had just completed the learning curve and was considered beginner. In terms of operative times, the docking time of the center that completed the learning curve was significantly lower $(\mathrm{P}=0.002)$. Total operative time was $129.3 \pm 49.3 \mathrm{~min}$ in Ege and $147.1 \pm 43.5 \mathrm{~min}$ in Bakirkoy $(\mathrm{P}=0.06)$. There was no significant difference between mean surgical setup times. Mean blood loss was $59.9 \pm 11.2 \mathrm{~mL}$. The robotic operation could not be completed in 5 patients. Four patients were converted to open surgery due to bleeding, while 1 patient was converted to conventional laparoscopy due to an overlap of the robotic arms. Evaluation of postoperative complications with Clavien Dindo classification demonstrated that 5 patients were classified as class I and 5 patients were classified as class IIIb. Mean postoperative length of hospital stay was $2.7 \pm 1.5$ days (Table 2).

Intraoperative complications were observed in 8 patients and in 10 patients complications arose postoperatively. Intraoperative complications included splenic injury $(n=2)$, bleeding $(n=3)$, diaphragmatic injury $(n=1)$ and hematoma in the serosa of the left colon was observed in the remaining 1 patient. The diaphragmatic injury was sutured robotically. One patient was converted to conventional laparoscopy due to the overlap of robotic arms, and the operation was completed without any problems. Postoperative wound infection was the most frequent complication (Table 3).

The most common finding in final histopathology report was adrenocortical adenoma, which was observed in 55 $(49.5 \%)$ patients, and the second most common finding was pheochromocytoma, which was observed in 35 (31.5\%) patients (Table 4). 
Table 1 Demographics and clinical characteristics of merged RA serie and of each center separately

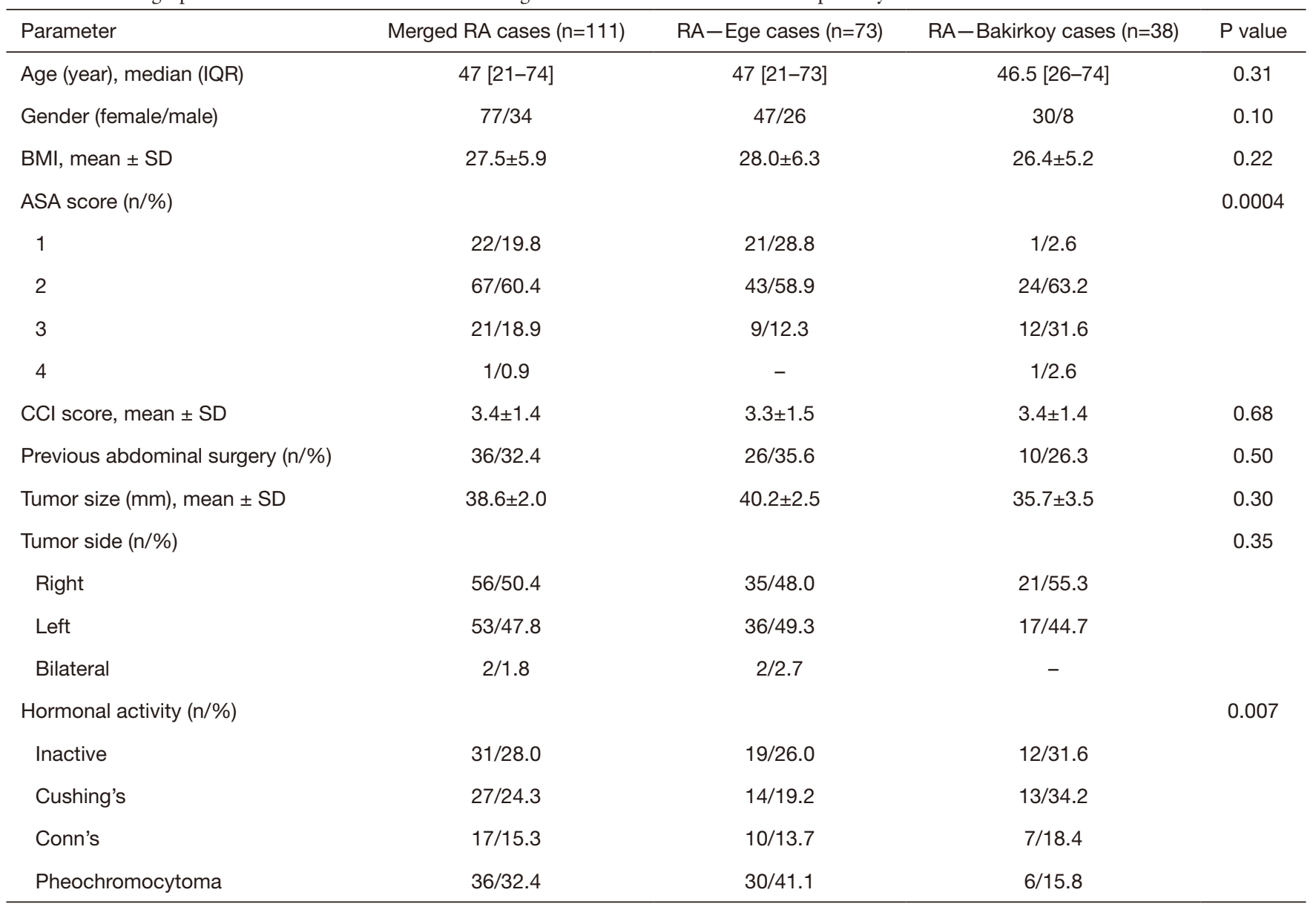

RA, robotic adrenalectomy; SD, standard deviation; IQR, interquartile range; ASA, American Society of Anaesthesiologists; BMI, body mass index; $\mathrm{CCl}$, Charlson Co-morbidity Index.

Table 2 Perioperative outcomes of merged RA serie and each center separately

\begin{tabular}{|c|c|c|c|c|}
\hline Parameter & Merged RA cases $(n=111)$ & RA-Ege cases $(n=73)$ & RA-Bakirkoy cases $(n=38)$ & $P$ value \\
\hline Surgical setup time $(\mathrm{min})$, mean $\pm \mathrm{SD}$ & $30.35 \pm 16.5$ & $32.1 \pm 16.4$ & $26.8 \pm 16.1$ & 0.11 \\
\hline Docking time (min), mean \pm SD & $9.4 \pm 5.5$ & $8.28 \pm 5.8$ & $11.6 \pm 4.0$ & 0.002 \\
\hline Console time (min), mean \pm SD & $92.1 \pm 38.3$ & $84.0 \pm 40.2$ & $107.6 \pm 28.9$ & 0.002 \\
\hline Conversion to laparoscopy or open (n/\%) & $5 / 4.5$ & $5 / 6.8$ & - & 0.03 \\
\hline Intraoperative complications (n/\%) & $8 / 7.2$ & $6 / 8.22$ & $2 / 5.3$ & 0.55 \\
\hline LOS (day), mean \pm SD & $2.7 \pm 1.5$ & $2.6 \pm 1.4$ & $2.9 \pm 1.9$ & 0.27 \\
\hline \multicolumn{5}{|l|}{ Postoperative complications (n/\%) } \\
\hline
\end{tabular}

RA, robotic adrenalectomy; SD, standard deviation; EBL, estimated blood loss; LOS, length of hospital stay. 
Table 3 Intraoperative and postoperative complications

\begin{tabular}{ll}
\hline Intraoperative complication $(\mathrm{n}=8)$ & Postoperative complication $(\mathrm{n}=10)$ \\
\hline Spleen injury [2] & Adrenal insufficiency [1] \\
Bleeding [3] & Incisional hernia [1] \\
Collision of robotic arms [1] & Wound infection [6] \\
Diaphragm injury (robotic repair) [1] & Atelectasis [1] \\
Hematoma in the left colon serosa [1] & Urinary tract infection [1] \\
\hline
\end{tabular}

Table 4 Final histopathology results of patients

\begin{tabular}{lc}
\hline Final pathology results & $\mathrm{n} / \%$ \\
\hline Pheochromocytoma & $35 / 31.5$ \\
Adrenal cortical adenoma & $55 / 49.5$ \\
Ovarian cancer metastasis & $1 / 0.9$ \\
Myelolipoma & $4 / 3.6$ \\
Ganglioneuroma & $1 / 0.9$ \\
Hematoma & $2 / 1.8$ \\
Adrenal cyst & $4 / 3.6$ \\
Retroperitoneal paraganglioma & $1 / 0.9$ \\
Lung adenocarcinoma & $2 / 1.8$ \\
Adrenal cortical nodular hyperplasia & $5 / 4.5$ \\
Adrenal cortical tumor with uncertain malignancy potential (borderline) & $1 / 0.9$ \\
\hline
\end{tabular}

The first 20 cases were considered as the learning period for each institution. The analysis of the learning period and the post-learning period for both centers demonstrated that total surgery time decreased from $152.68 \pm 48.6$ to $118.8 \pm 37.1 \mathrm{~min}$, and the console time decreased from $113.2 \pm 38.9$ to $81.6 \pm 35.1 \mathrm{~min}(\mathrm{P}<0.0001)$. No significant decrease in the docking time was observed in the combined data. Individual assessment of the centers demonstrated that total operative time decreased from $145.1 \pm 48.9$ to $113.8 \pm 37.6 \mathrm{~min}$, and the console time decreased from $109.1 \pm 42.3$ to $73.6 \pm 34.6 \mathrm{~min}(\mathrm{P}=0.0005)$ in Ege. At Bakirkoy, total operation time decreased from $160.7 \pm 48.1$ to $132.0 \pm 32.9 \mathrm{~min}(\mathrm{P}=0.04)$, docking time decreased from $13.4 \pm 4.2$ to $9.7 \pm 2.9 \mathrm{~min}(\mathrm{P}=0.004)$, and the console time decreased from $117.5 \pm 35.6$ to $102.8 \pm 27.3 \mathrm{~min}(\mathrm{P}=0.16)$ (Table 5 and Figure 3).

The requirement for an extra trocar, conversion to laparoscopy, conversion to open surgery, and intraoperative and postoperative complications were compared between the learning curve period and the post-learning curve period. In Ege, the requirement for an extra trocar in the learning curve period was observed in 2 cases $(\mathrm{P}=0.0001)$. Conversion to laparoscopy was conducted in 1 case during the post-learning curve period $(\mathrm{P}=0.09)$. No significant difference was determined between the two periods based on conversion to open surgery, and intraoperative and postoperative complications (Table 6).

The merged series was evaluated for the rate of conversion to laparoscopy or open surgery, intraoperative and postoperative complications, and re-hospitalization by age, tumor diameter, BMI and total operation time using the threshold values for each parameter. The intraoperative complication rate was $28 \%$ in patients with a tumor diameter greater than $50 \mathrm{~mm}(\mathrm{P}<0.0001)$. Furthermore, a tumor diameter greater than $50 \mathrm{~mm}$ increased the rate of conversion to open or laparoscopic surgery, postoperative 
Table 5 Comparison of operative outcomes by experience (merged RA series and each center's separately)

\begin{tabular}{lcc}
\hline Parameter & Learning curve period* $(n=40)$ & ${\text { Post-learning curve period }{ }^{\star \star}(n=71)}^{P}$ value \\
\hline Total operative time $($ min), mean \pm SD & $152.68 \pm 48.6$ & $118.8 \pm 37.1$ \\
Merged series & $145.1 \pm 48.9$ & $113.8 \pm 37.6$ \\
Ege & $160.7 \pm 48.1$ & $132.0 \pm 32.9$ \\
Bakirkoy & & 0.0005 \\
Docking time (min), mean \pm SD & $9.68 \pm 0.9$ & $9.6 \pm 0.7$ \\
Merged series & $6.1 \pm 0.9$ & $9.6 \pm 0.9$ \\
Ege & $13.4 \pm 4.2$ & $9.7 \pm 2.9$ \\
Bakirkoy & & 0.94 \\
Console time (min), mean \pm SD & $113.2 \pm 38.9$ & 0.03 \\
Merged series & $109.1 \pm 42.3$ & 0.004 \\
Ege & $117.5 \pm 35.6$ & $73.6 \pm 34.6$ \\
Bakirkoy & $102.8 \pm 27.3$ \\
\hline
\end{tabular}

*, first 20 cases in both institutions were counted in learning curve period; ${ }^{* *}, 53$ of 71 cases in post learning curve period from Ege, remaining 18 cases from Bakirkoy.
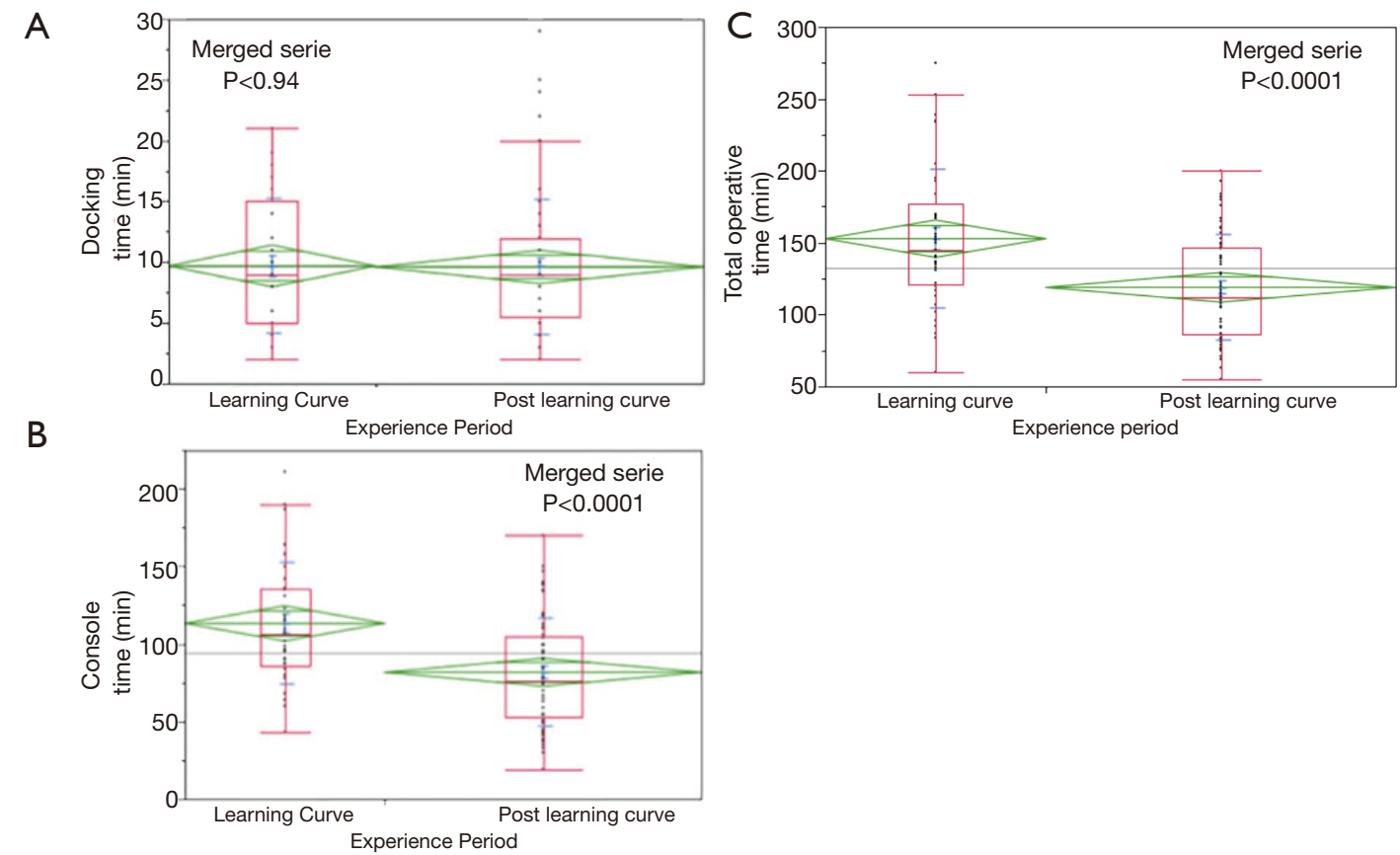

Figure 3 Comparison of operative outcomes by experience: docking time (A), console time (B), total operative time (C).

complications, and re-hospitalization $(\mathrm{P}=0.076, \mathrm{P}=0.422$, $\mathrm{P}=0.205$, respectively). Similarly, an increase was identified in all above-mentioned four parameters when the total operation time was more than 110 minutes $(\mathrm{P}=0.432$, $\mathrm{P}=0.305, \mathrm{P}=0.165, \mathrm{P}=0.165$; respectively, Table 7).

\section{Discussion}

LA is the most widely preferred method in surgical treatment of adrenal gland diseases. Technological developments in laparoscopic surgery introduced significant use of robotic systems in these procedures. Several studies 
Table 6 Detailed comparison of perioperative outcomes by experience (merged RA series and each center separately)

\begin{tabular}{|c|c|c|c|}
\hline Parameter & Learning curve period ${ }^{*}(n=40)$ & Post-learning curve period ${ }^{\star \star}(n=71)$ & $P$ value \\
\hline Merged series & $2^{\ddagger} / 5$ & - & 0.07 \\
\hline Ege & $2 / 10$ & - & 0.0001 \\
\hline Bakirkoy & - & - & $\mathrm{N} / \mathrm{A}$ \\
\hline \multicolumn{4}{|c|}{ Conversion to laparoscopy (n/\%) } \\
\hline Merged series & - & $1 / 1$ & 0.23 \\
\hline Ege & - & $1 / 2$ & 0.09 \\
\hline Bakirkoy & - & - & $\mathrm{N} / \mathrm{A}$ \\
\hline \multicolumn{4}{|c|}{ Conversion to open (n/\%) } \\
\hline Bakirkoy & - & - & N/A \\
\hline \multicolumn{4}{|c|}{ Intraoperative complications (n/\%) } \\
\hline Merged series & $3 / 7.5$ & $5 / 7$ & 0.78 \\
\hline Ege & $2 / 10$ & $4 / 7.5$ & 0.61 \\
\hline Bakirkoy & $1 / 5$ & $1 / 5.5$ & 0.75 \\
\hline \multicolumn{4}{|c|}{ Postoperative complications ( $\mathrm{n} / \%$ ) } \\
\hline Merged series & $4 / 10$ & $6 / 8.5$ & 0.62 \\
\hline Ege & $3 / 15$ & $4 / 7.5$ & 0.11 \\
\hline
\end{tabular}

*, the first 20 cases from both institutions were counted in learning curve period; ${ }^{\star \star}, 53$ of 71 cases in post learning curve period from Ege, remaining 18 cases from Bakirkoy; ${ }^{\dagger}$, placement of 5 trocars for Right RA and 4 trocars for Left RA was considered as initial trocar setup for relevant side. Placement of additional trocars from initial setup was considered as "requirement of extra trocar"; ${ }^{\ddagger}$, these two cases were bilateral and a total of 7 trocars were used per case.

Table 7 The effects of age, tumour diameter, BMI, and total surgery time on complications.

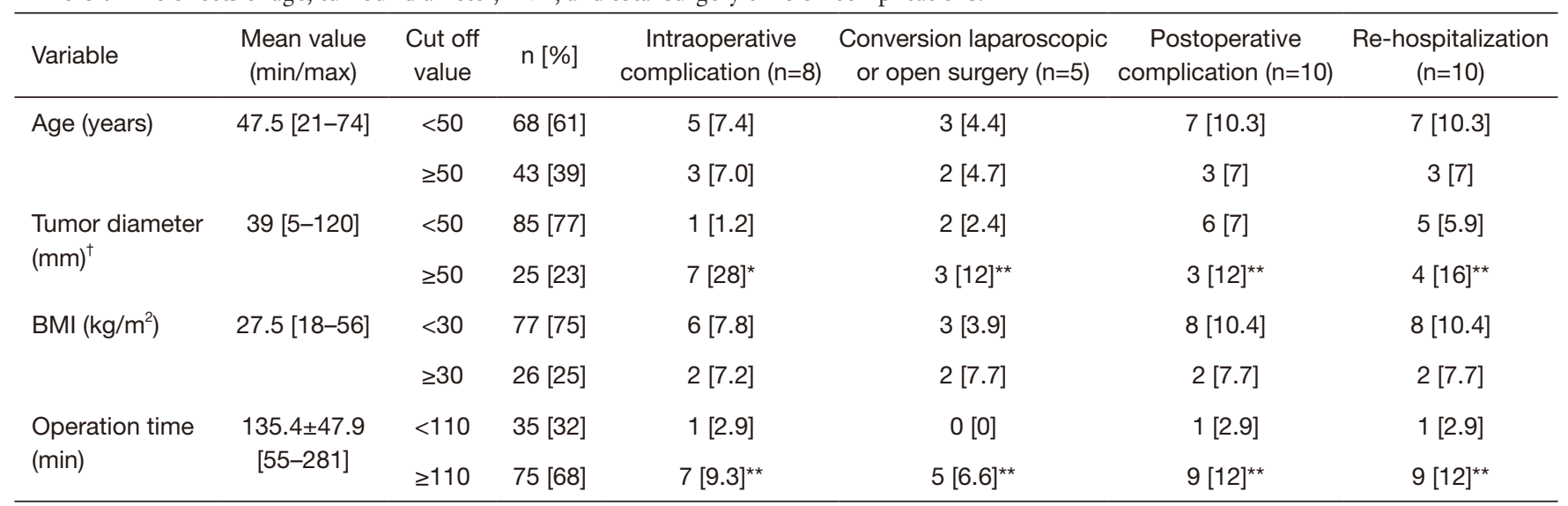

${ }^{\dagger}$, one patient had bilateral adrenal hyperplasia; ${ }^{*}, \mathrm{P}<0.0001 ;{ }^{* \star}, \mathrm{P}<0.5$. 
in the literature compared LA and RA methods. These studies mainly concluded that RA was safer and feasible with acceptable outcomes in adrenal gland surgery $(15,16)$. In our study, the merged outcomes of RA cases from two high-volume endocrine surgery centers ( 40 cases per year) were investigated. During the assessments, we also investigated whether the number of surgeries performed with RA and increased experience of surgeons had an effect on the operation time and the complication rate.

In current literature, there is no difference in tumor size threshold for patient selection in both techniques, and any candidate eligible for conventional laparoscopic surgery is also eligible for robotic surgery. In our study, it was observed that the mean tumor diameter was $38.6 \pm 2.0 \mathrm{~mm}$, which was comparable to the mean figure reported in the literature $(10,17)$. Thirty-six patients $(32.4 \%)$ had a history of abdominal surgery and it was shown that this did not present an obstacle for robotic transperitoneal adrenalectomy and posed no additional complication risk $(18,19)$. Estimated blood loss $(59.9 \pm 11.2 \mathrm{~mL})$, conversion to open or laparoscopic surgery rate $(4.5 \%)$ and length of hospital stay $(2.7 \pm 1.5$ days $)$ were consistent with the data reported in the literature (10). We encountered intraoperative bleeding in 3 of our patients and similar to our findings, bleeding was the most common complication observed in adrenal surgery in the literature $(10,17,20)$. One patient was converted to laparoscopic surgery due to collision of robotic arms. This technical complication could be prevented by placing the trocars at a proper distance $(\sim 10 \mathrm{~cm})$ from each other and measuring and marking the trocar sites before the incision. Postoperative complications in adrenal gland surgery could be categorized into two complication types: surgical complications and complications due to hormonal deficiency. We had 6 (5.4\%) wound site infections in our series, which was a higher number than expected. As adrenal surgery is classified as a clean surgery (21), the present study rate could be considered high; however, no data were reported in the literature, which indicated the fact that robotic surgery increased surgical site infection. We had only one patient with adrenal insufficiency.

Duration of surgery is one of the most frequently criticized issues in RA. Compared to laparoscopic approach, there is an additional docking period in RA. The literature review demonstrated that the average total operation time varied between 89 and 237 minutes. In our study, it was determined that the mean duration of operation at both centers was $135.4 \pm 47.9$ minutes. Individual assessment of the two centers demonstrated a significant difference between the docking and console times $(\mathrm{P}=0.002)$. This difference could be explained by the fact that Ege operated on more cases after they completed the learning curve when compared to Bakirkoy.

Contrasting data were observed in the literature on RA learning curve. Brunaud et al. reported that 20 cases should be sufficient, while D'Annibale et al. stated that their learning curve lasted for 12 cases $(8,9)$. In the present study, the first 20 cases at both centers were evaluated individually as well as in the merged series. In the merged series, it was found that the decrease in total operative time after the first 40 cases was statistically significant $(\mathrm{P}=0.0001)$. In particular, it was observed that the change was significant for the console time, which is expected to decrease more with the increase in experience $(\mathrm{P}=0.0001)$. This finding was consistent with previous studies. Robotic surgeries require experienced robotic surgeons and a well-equipped team for proper installation of the system and to tackle potential problems preoperatively. Both the set-up and docking times included in the total operative time depend on the training level and experience of the assisting team. In the present study, since both institutions are teaching institutions, the number of team members who performed these installations varied. Differences in training were reflected on the set-up and docking times. In our study, the docking time at Ege training series increased after the learning curve period. The reason for this increase could be associated with the training provided for the assisting team. In the present study, this was one of the weaknesses in standardization.

In our study, the impacts of the learning curve on extra trocar requirement, conversion to laparoscopy or open surgery, and intraoperative and postoperative complications were also analyzed. During the learning period, two cases required one extra trocar $(\mathrm{P}=0.0001)$. There was no significant difference in other parameters between the two periods. RA surgery is performed by endocrine surgeons who already have endoscopic surgical experience in highvolume centers. The learning curve of the surgeon does not depend on the applicability of the surgery, but on the application of different instrument systems. Thus, there was no difference between the learning curve period and the post-learning curve period complication rates. The literature on the comparison of LA and RA reported a similar complication rate between the two $(6,16,22)$.

In the present study, age, tumor diameter, BMI, and operation duration, which could increase the complication rate in $\mathrm{RA}$, were evaluated separately. Based on 
intraoperative and postoperative complications, conversion to laparoscopic or open surgery, and re-hospitalization, there were no significant differences between the groups that included patients who were younger and older than 50 years and patients with a BMI of under and over 30 . There are reports that demonstrated that the operative time in RA is shorter when compared to LA in patients with a BMI of over 30 (22). Agcaoglu et al. reported that BMI affected neither operation time nor the complication rates (13).

In the current study, it was demonstrated that a tumor diameter of greater than $50 \mathrm{~mm}$ was a crucial factor in the development of intraoperative complications $(\mathrm{P}<0.0001)$. Furthermore, it was found that conversion to open surgery, postoperative complications, and rehospitalization rates were higher but the differences were not significant. Previously, Greilsamer et al. showed that a tumor diameter greater than $50 \mathrm{~mm}$ was an important predictor of conversion to open surgery, and it increased the complication rates. Thus, it is recommended that tumors greater than $50 \mathrm{~mm}$ should be referred to high-volume endocrine surgery centers (18).

The advantages of the robotic surgical system such as bimanual wristed instrumentation, three-dimensional highdefinition view, tremor-filtration, and individual camera operation are well documented. However, there are also disadvantages such as lack of tactile feedback and costeffectiveness. It can be predicted that these disadvantages will be solved with technological advances, and the system will acquire several new advantages.

In conclusion, the operation time, which is a critical issue in robotic surgery, decreases as the level of experience increases. We suggest that masses greater than $50 \mathrm{~mm}$ should be evaluated more carefully due to increased intraoperative complication risk, especially in the beginning of the learning curve. The present study assessed the outcomes of 111 cases and demonstrated that RA was a lowmorbidity, safe, and effective procedure without mortality.

\section{Acknowledgments}

Funding: None.

\section{Footnote}

Provenance and Peer Review: This article was commissioned by the Guest Editor (Özer Makay) for the series "Robotic Adrenalectomy" published in Gland Surgery. The article was sent for external peer review organized by the Guest Editor and the editorial office.

Conflicts of Interest: All authors have completed the ICMJE uniform disclosure form (available at http:// dx.doi.org/10.21037/gs.2020.02.21). The series "Robotic Adrenalectomy" was commissioned by the editorial office without any funding or sponsorship. $\mathrm{OZ}$ served as the unpaid Guest Editor of the series and serves as an unpaid editorial board member of Gland Surgery from May 2019 to Apr 2021.

Ethical Statement: The authors are accountable for all aspects of the work in ensuring that questions related to the accuracy or integrity of any part of the work are appropriately investigated and resolved. All procedures conducted in this study that involved human subjects were in accordance with the ethical standards depicted by the Bakirkoy Dr. Sadi Konuk Training and Research Hospital Ethics Committee (Registration Nr: 2019-01-19), with the 1964 Helsinki Declaration and later amendments, and compatible ethical standards. Informed consent was obtained from all participants in the study.

Open Access Statement: This is an Open Access article distributed in accordance with the Creative Commons Attribution-NonCommercial-NoDerivs 4.0 International License (CC BY-NC-ND 4.0), which permits the noncommercial replication and distribution of the article with the strict proviso that no changes or edits are made and the original work is properly cited (including links to both the formal publication through the relevant DOI and the license). See: https://creativecommons.org/licenses/by-nc-nd/4.0/.

\section{References}

1. Gagner M, Lacroix A, Bolte E. Laparoscopic adrenalectomy in Cushing's syndrome and pheochromocytoma. N Engl J Med 1992;327:1033.

2. Mercan S, Seven R, Ozarmagan S, et al. Endoscopic retroperitoneal adrenalectomy. Surgery 1995;118:1071Y1075.

3. Guazzoni G, Montorsi F, Bocciardi A, et al. A Transperitoneal laparoscopic versus open adrenalectomy for benign hyperfunctioning adrenal tumors: a comparative study. J Urol 1995;153:1597-600.

4. Wu JC, Wu H, Lin M, et al. Comparison of robot-assisted laparoscopic adrenalectomy with traditional laparoscopic adrenalectomy - 1 year follow-up. Surg Endosc 
2008;22:463-6.

5. Henry JF. Minimally invasive adrenal surgery. Best Pract Res Clin Endocrinol Metab 2001;15:149-60.

6. Economopoulos KP, Mylonas KS, Stamou AA, et al. Laparoscopic versus robotic adrenalectomy: A comprehensive meta-analysis. Int J Surg 2017;38:95-104.

7. Guerrieri M, Campagnacci R, De Sanctis A, et al. The learning curve in laparoscopic adrenalectomy. J Endocrinol Invest 2008;31:531-6.

8. Brunaud L, Bresler L, Ayav A, et al. Robotic-assisted adrenalectomy: what advantages compared to lateral transperitoneal laparoscopic adrenalectomy? Am J Surg 2008;195:433-8.

9. D'Annibale A, Lucandri G, Monsellato I, et al. Robotic adrenalectomy: technical aspects, early results and learning curve. Int J Med Robot 2012;8:483-90.

10. Makay O, Erol V, Ozdemir M. Robotic adrenalectomy. Gland Surg 2019;8:S10-6.

11. Aksoy E, Taskin H, Aliyev S, et al. Robotic versus laparoscopic adrenalectomy in obese patients. Surg Endosc 2013;27:1233-6.

12. Taskin HE, Aliyev S, Aksoy E, et al. Bilateral posterior retroperitoneal robotic adrenalectomy for ACTHindependent Cushing syndrome. Surg Laparosc Endosc Percutan Tech 2014;24:e113-5.

13. Agcaoglu O, Akbas M, Ozdemir M, et al. The Impact of Body Mass Index on Perioperative Outcomes of Robotic Adrenalectomy: An Update. Surg Innov 2019;26:687-91.

14. Akarsu C, Dural AC, Kankaya B, et al. The early results of our initial experience with robotic adrenalectomy. Ulus Cerrahi Derg 2014;30:28-33.

Cite this article as: Ozdemir M, Dural AC, Sahbaz NA, Akarsu C, Uc C, Sertoz R, Alis H, Makay O. Robotic transperitoneal adrenalectomy from inception to ingenuity: the perspective on two high volume endocrine surgery centers. Gland Surg 2020;9(3):815-825. doi: 10.21037/gs.2020.02.21
15. Agrusa A, Romano G, Navarra G, et al. Innovation in endocrine surgery: robotic versus laparoscopic adrenalectomy. Meta-analysis and systematic literature review. Oncotarget 2017;8:102392-400.

16. Morelli L, Tartaglia D, Bronzoni J, et al. Robotic assisted versus pure laparoscopic surgery of the adrenal glands: a case-control study comparing surgical techniques. Langenbecks Arch Surg 2016;401:999-1006.

17. Taskin HE, Berber E. Robotic adrenalectomy. Cancer J 2013;19:162-6.

18. Greilsamer T, Nomine-Criqui C, Thy M, et al. Roboticassisted unilateral adrenalectomy: risk factors for perioperative complications in 303 consecutive patients. Surg Endosc 2019;33:802-10.

19. Quadri P, Esposito S, Coleoglou A, et al. Robotic Adrenalectomy: Are We Expanding the Indications of Minimally Invasive Surgery? J Laparoendosc Adv Surg Tech A 2019;29:19-23.

20. Nomine-Criqui C, Brunaud L, Germain A, et al. Robotic lateral transabdominal adrenalectomy. J Surg Oncol 2015;112:305-9.

21. Kijima T, Masuda H, Yoshida S, et al. Antimicrobial prophylaxis is not necessary in clean category minimally invasive surgery for renal and adrenal tumors: a prospective study of 373 consecutive patients. Urology 2012;80:570-5.

22. Chai YJ, Kwon H, Yu HW, et al. Systematic Review of Surgical Approaches for Adrenal Tumors: Lateral Transperitoneal versus Posterior Retroperitoneal and Laparoscopic versus Robotic Adrenalectomy. Int J Endocrinol 2014;2014:918346. 